\title{
The Adaptation Experiences of Hong Kong and Caribbean Adolescent Immigrants in Canada: A Multivariate Analysis
}

\author{
Henry P.H. Chow, PhD \\ Department of Sociology and Social Studies, University of Regina \\ Regina, Saskatchewan, Canada \\ Henry.Chow@uregina.ca
}

\begin{abstract}
This article explores the adaptation experiences of minority adolescent immigrants in Canada. A total of 368 Hong Kong and 63 Caribbean immigrant students attending 28 different high schools under the jurisdiction of 6 school boards in Toronto took part in a self-administered questionnaire survey. The findings demonstrated substantial differences in adaptation experiences among the two groups. Results of the multiple ordinary least-squares regression analysis indicated that political reasons for emigration, economic reasons for emigration, presence of a parent in Canada, prior experience in Canada, experience in making friends with Canadians, and ethnic background were found to be significantly related adaptation. More specifically, respondents who stressed the importance of political or economic reasons for emigration, visited Canada as a tourist or studied in Canada on student authorization prior to emigration, expressed more favourable experience in making friends with Canadians, reported having at least one parent residing in Canada, and emigrated from the Caribbean were found to demonstrate a more positive overall adaptation experience.
\end{abstract}

Keywords: adaptation; emigration; Hong Kong and Caribbean immigrants; Canada

\section{INTRODUCTION}

Migratory movements and settlement across geographic boundaries are social processes that are historically conditioned. The massive exodus of Hong Kong people during the late 1980s and 1990s was due primarily to the impending political change in 1997, the year in which the People's Republic of China (PRC) resumed the exercise of sovereignty over Hong Kong after 156 years of British administration. The critical issue of concern revolved around whether this British Crown colony could be successfully absorbed into the PCR without threatening and disrupting its social, political, educational, and economic systems. Notably, Hong Kong was the top source of all immigrants to Canada during the period 1990-97. According to the 2001 census, the Chinese became the largest visible minority group in this country. Of the 1,029,400 who identified themselves as Chinese, 409,500 resided in the Toronto census metropolitan area (Statistics Canada, 2003). The most recent Canadian National Household Survey reveals that the number of individuals who identified themselves as Chinese increased from 1,347,600 in 2006 to 1,487,580 in 2011, forming $21.1 \%$ of the visible minority population and 4\% of Canada's total population (Statistics Canada, 2013).

A review of the literature reveals that young Chinese immigrants in North America face formidable personal challenges, including high parental expectations of their academic and occupational achievement (Chen et al., 2015; Chen \& Lan 1998; Crystal et al., 1994; Eng et al., 2008; Liu, Benner, Lau, \& Kim, 2009; Tang, 2002), discrimination experiences (Benner \& Kim, 2009; Goto, Gee, \& Takeuchi, 2002; Juang \& Alvarez, 2010; Juang \& Cookston, 2009), intergenerational conflicts (Chan \& Leong, 1994; Fu, 2002), language barriers (Lee \& Chen, 2000; Yeh \& Inose, 2002), psychological problems (Florsheim, 1997; Fuligni, Yip, \& Tseng, 2002; Lin, Endler, \& Kocovski, 2001; Qin, 2008), life satisfaction (Lee \& Kimberlin, 2015), and cultural differences (James, 1997; Schnittker, 2002; Suzuki \& Greenfield, 2002).

Comparatively speaking, the immigration and adaptation experiences of the Hong Kong Chinese adolescent immigrants in Canada have received limited research attention. Previous studies have demonstrated the importance of social support in adaptation (Leung, 2001) and the positive relationship between ethnic identity and self-esteem (Lay \& Verkuyten, 1999), and have explored the process of acculturation and adjustment (Chataway \& Berry, 1989; Dyal \& Chan, 1985; Lam, 2001; Minichiello, 2001; Yeung, 2005), and academic achievement (Samuel et al., 2001) among young 
The Adaptation Experiences of Hong Kong and Caribbean Adolescent Immigrants in Canada: A Multivariate Analysis

Hong Kong immigrants. To extend this line of research and to fill a gap in the literature, the purpose of this paper is to explore the adaptation experiences of adolescent Hong Kong immigrants, using a small sample of immigrant students from the Caribbean as a comparison group.

\section{THEORETICAL MODEL}

A multivariate model of immigrant adaptation was developed by Goldlust and Richmond (1974) to study the adaptation of immigrants, taking into account the pre-migration characteristics and conditions and the situational determinants in receiving country. The development of a multivariate model was based primarily on a recognition of the fact that human behaviour is the complex outcome of various determinants and only a very few of these can be adequately observed. As Goldlust and Richmond's model was developed to understand the adaptation of immigrants in general, a modified version of this model was used as the theoretical framework for the present study of immigrant students (see Figure 1).

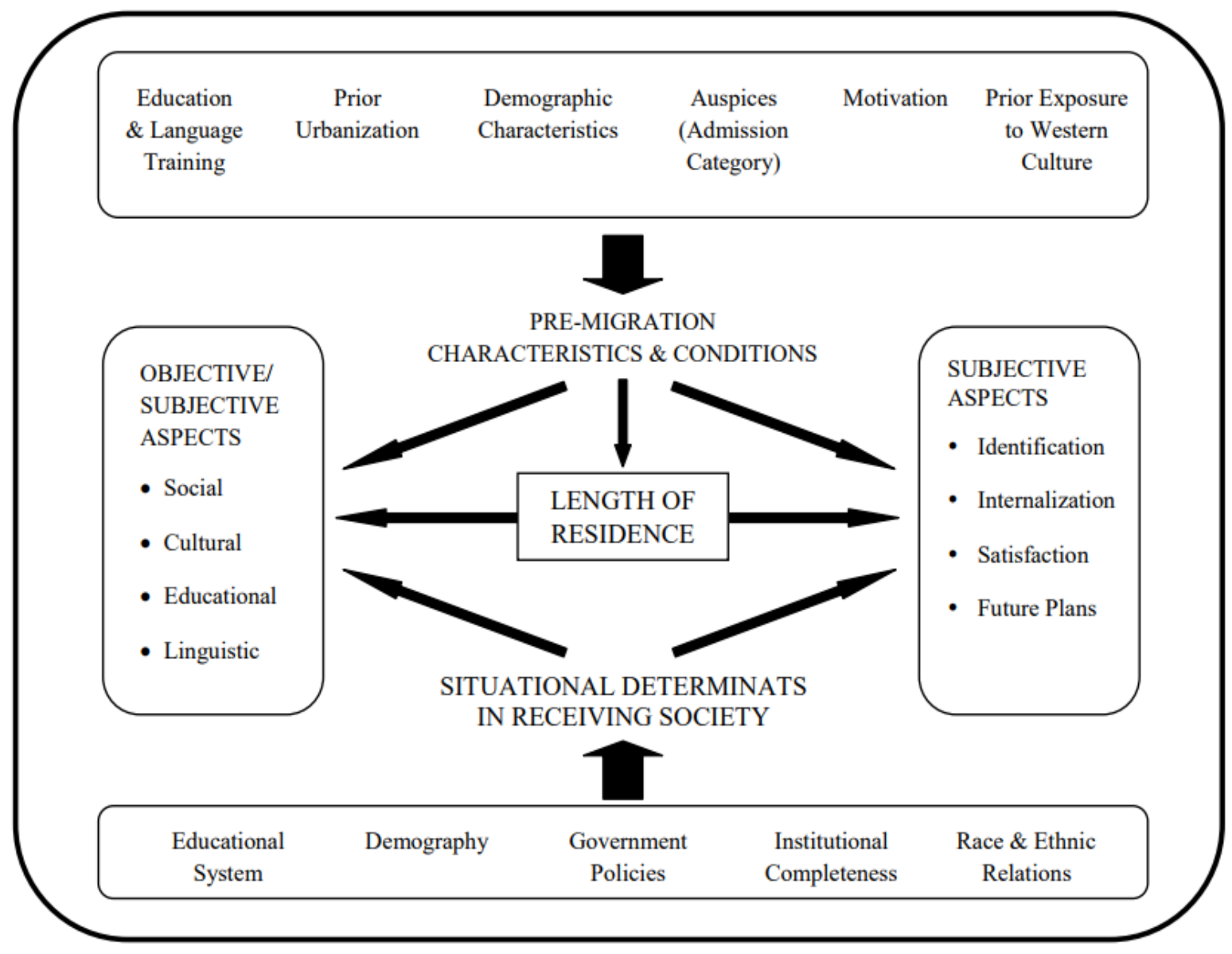

Figure1. Multivariate model of immigrant student adaptation

In terms of the pre-immigration characteristics and conditions, in addition to the original five factors (i.e., education and technical training, prior urbanization, demographic characteristics, admission category, and motivation), prior exposure to Western culture has been added. This would be vital as some immigrant students may have studied in foreign countries prior to emigration. The original six situational determinants in the receiving country (i.e., demography, urbanization, industrialization, government policies, pluralism, and stratification) have also been modified to include institutional completeness (i.e., presence of ethnic institutions), educational system, and race and ethnic relations.

With respect to the specific measures of adaptation, the original model focuses on four objective aspects of adaptation (i.e., political, social, cultural, and economic). The revised one has replaced the political and economic dimensions by educational and linguistic aspects. These four aspects would be treated as both subjective and objective elements in the new model. Concerning the subjective measures of adaptation, in addition to the inclusion of the original three elements of identification (i.e., modification of the immigrant's own sense of identity and a transference of loyalty from the 
country of origin to the new), internalization (i.e., the process of change in the attitudes and values of the immigrant and is regarded as a component of the socialization process), and satisfaction (i.e., relative comparisons with the immigrant's situation prior to migration as well as with other immigrants and with members of the receiving society), the future plans of the immigrant students has been added. This is crucial because their plans for permanent settlement in Canada or for returning to their homeland would influence their commitment to improve their language skills, the degree of participation in various formal organizations, the types of social network developed, and their commitment to the receiving country.

\section{METHOD}

\subsection{Sample}

The data for the present analyses were based on a questionnaire survey of 368 Hong Kong and 63 Caribbean immigrant students in Toronto (Chow, 2007, 1997). The two major eligibility criteria for participation in the study included length of residence in Canada of fewer than five years and legal status in Canada as a permanent resident (i.e., landed immigrant or citizen). The Hong Kong sample comprised $176(48.0 \%)$ male and $191(52.0 \%)$ female students, with a mean age of 17.83 years $(S D=$ 2.88). Prior to obtaining landed immigrant status, $26.2 \%$ of the students $(n=95)$ had visited Canada as a tourist and 6.4\% $(n=23)$ had studied in Canada on student authorization. In terms of immigration admission category, about two-fifths $(n=130,37.1 \%)$ came to Canada with their parents under business class (investor or entrepreneur), one-quarter $(24.9 \%)$ came under the self-employment or independent category, two-fifths $(n=73,20.7 \%)$ were admitted under family class, and one-fifth $(n=$ $31,8.9 \%$ ) belonged to the "assisted relatives" classification.

\subsection{Comparison Group}

A small group of Black immigrant students from the Caribbean was used as a comparison group so as to better understand the uniqueness of the adaptation experiences among the Chinese immigrant students. Indeed, immigrant students from Hong Kong and the Caribbean share some similarities and dissimilarities. These students are similar in the sense that the countries from which they come have different historical experiences of colonization. However, the distinct physical characteristics of these two groups of students set them apart from members of the mainstream society in Canada. There are also significant differences between these two groups in terms of their cultural and language backgrounds. The 63 Caribbean students were recruited from 10 schools under the jurisdiction of 3 school boards in Toronto. This sample comprised 21 male (33.9\%) and 41 female students $(66.1 \%)$, with a mean age of 17.02 years $(S D=2.74)$. Almost three-fifths $(n=32,55.1 \%)$ came as family class immigrants, and about a quarter $(n=14,24.1 \%)$ were admitted under the category of "assisted relatives."

\subsection{Statistical Analysis}

The Statistical Package for the Social Sciences was used to analyze the data. Descriptive and inferential analyses were conducted. Cronbach's alpha reliability test was employed to explore the internal consistency of all scales used. Cross-tabulation was used to explore the relationship between categorical variables. Analysis of variance (ANOVA) and multivariate analysis of variance (MANOVA) were used to compare the mean scores of the various scales between the two student groups. A multiple ordinary least-squares (OLS) regression model was constructed to identify the key determinants of overall adaptation.

\section{FindingS}

The immigration and adaptation experiences of the Hong Kong and Caribbean immigrant students will be discussed under the following major sections: perceived motivations for emigration, educational aspects of adaptation, social aspects of adaptation, cultural and linguistic aspects of adaptation, internalization, identification, general gratification with life, discrimination experience, future plans, multivariate analysis of adaptation, and overall adaptation experiences.

\subsection{Perceived Motivations for Emigration}

The motivations for emigration scale was developed to explore immigrant students' perceptions of their families' motivations to emigrate to Canada, including social, educational, economic, political, cultural, and personal factors using a five-point scale ranging from $1=$ very unimportant to $5=$ very important. As shown in Table 1, the top three reasons provided by the Hong Kong students included 
The Adaptation Experiences of Hong Kong and Caribbean Adolescent Immigrants in Canada: A Multivariate Analysis

(1) more university or college places in Canada $(M=4.26, S D=.90)$; (2) uncertain political future of home country $(M=3.70, S D=1.24)$; and (3) better educational opportunities in Canada $(M=3.88$, $S D=1.09$ ), whereas the three major reasons given by the Caribbean students were (1) better educational opportunities in Canada $(M=4.51, S D=.92)$; (2) more university or college places in Canada $(M=4.35, S D=.97)$; and (3) a wider choice of fields in Canada $(M=4.31, S D=1.19)$. A one-way MANOVA was executed to examine differences in the major reasons given by the Chinese and Caribbean respondents for immigrating to Canada. A significant multivariate main effect was found (Wilks $\lambda=.752, F(6,413)=22.715, p<.001)$. The univariate F-tests of MANOVA show that educational $(F(1,418)=9.84, p<0.01)$, economic $(F(1,418)=62.18, p<.000)$, political $(F(1$, $418)=12.87, p<.000)$ and personal $(F(1,418)=20.99, p<.000)$ factors attained statistical significance. An examination of the mean values of these four categories reveals that the Hong Kong students placed greater emphasis on the political aspect, whereas the Caribbean students were more concerned with educational, economic, and personal factors. This finding is not surprising as the Hong Kong students were facing an uncertain political future in their place of origin.

Table1. Perceived motivations for emigration to Canada

\begin{tabular}{|c|c|c|c|c|}
\hline & \multicolumn{2}{|c|}{ Hong Kong } & \multicolumn{2}{|c|}{ Caribbean } \\
\hline & M & SD & M & SD \\
\hline \multicolumn{5}{|l|}{ Social Factors } \\
\hline 1. Better social welfare system in Canada. & 3.07 & 1.20 & 2.89 & 1.44 \\
\hline 2. Pollution problems in home country. & 2.74 & 1.19 & 2.84 & 1.33 \\
\hline 3. My home country is too overpopulated. & 2.73 & 1.25 & 2.35 & 1.31 \\
\hline 4. Life is too tense or hectic in home country. & 2.59 & 1.17 & 2.30 & 1.25 \\
\hline 5. Poor housing condition in home country. & 2.32 & 1.17 & 1.93 & .93 \\
\hline \multicolumn{5}{|l|}{ Educational Factors } \\
\hline 1. More university or college places in Canada. & 4.26 & .90 & 4.51 & .92 \\
\hline 2. Better educational opportunities in Canada. & 3.88 & 1.09 & 4.35 & .97 \\
\hline 3. A wider choice of fields in Canada. & 3.84 & 1.05 & 4.31 & 1.19 \\
\hline \multicolumn{5}{|l|}{ Economic Factors } \\
\hline 1. Better job opportunities in Canada. & 2.25 & 1.22 & 4.19 & 1.17 \\
\hline 2. Better investment opportunities in Canada. & 2.19 & 1.09 & 3.50 & 1.13 \\
\hline 3. Family owns business in Canada. & 2.13 & 1.13 & 1.91 & 1.07 \\
\hline \multicolumn{5}{|l|}{ Political Factors } \\
\hline 1. Uncertain political future of home country. & 3.70 & 1.24 & 3.53 & 1.24 \\
\hline 2. Human rights are highly respected in Canada. & 3.67 & 1.16 & 2.93 & 1.35 \\
\hline 3. Greater political freedom in Canada. & 3.44 & 1.16 & 2.71 & 1.26 \\
\hline \multicolumn{5}{|l|}{ Cultural Factors } \\
\hline 1. Canada is a multicultural society. & 3.32 & 1.24 & 3.32 & 1.26 \\
\hline 2. Many people of my ethnic origin are living in Canada. & 3.20 & 1.15 & 3.46 & 1.32 \\
\hline 3. Communities of my own ethnic groups are well- established in Canada. & 3.11 & 1.16 & 3.42 & 1.27 \\
\hline 4. Canada is an English-speaking country. & 3.09 & 1.20 & 2.88 & 1.21 \\
\hline \multicolumn{5}{|l|}{ Personal Factors } \\
\hline 1. Recommended by friends or relatives. & 3.04 & 1.19 & 4.20 & 1.02 \\
\hline 2. To join family members or relatives already in Canada. & 2.94 & 1.37 & 3.95 & 1.25 \\
\hline $\begin{array}{l}\text { 3. To prepare the way for remaining family members or relatives } \\
\text { to immigrate to Canada. }\end{array}$ & 2.85 & 1.33 & 3.47 & 1.22 \\
\hline 4. The prospects for personal advancement in Canada are better. & 2.76 & 1.27 & 2.64 & 1.30 \\
\hline 5. Recommended by immigration consultant/lawyer. & 2.44 & 1.13 & 2.42 & 1.43 \\
\hline 6. Came to Canada before as a visitor or student. & 2.27 & 1.28 & 2.42 & 1.43 \\
\hline 7. Unable to obtain landed immigrant status from other countries. & 2.09 & 1.13 & 2.24 & 1.35 \\
\hline
\end{tabular}

\subsection{Educational Aspects of Adaptation}

\subsubsection{Academic Performance and Major Area of Study}

The average mark of all courses completed in the previous term was an objective measure of students' academic performance. Nearly three-quarters of the Hong Kong students reported having obtained an "A" $(n=125,34.9 \%)$ or "B" $(n=140,39.1 \%)$ average. Among the Caribbean students, while nearly half $(n=26,48.1 \%)$ reported a "B" average, about one-fifth $(n=11,20.4 \%)$ obtained an average 
grade of "A." In addition, students' major area of study (i.e., area in which they have accumulated the most academic credits) in both homeland and in Canada was used to examine whether they were more inclined to enrol in courses which would require less English. A cross-tabulation analysis $\left(\chi^{2}=\right.$ 197.17, d.f. $=9, p<.001)$ revealed that a notable proportion of the Hong Kong students who focused on Arts subjects (i.e., language intensive courses) prior to immigration switched to other areas, with $26 \%(n=19)$ to science, $23.3 \%(n=17)$ to business, and $28.8 \%(n=21)$ to a combination of various subjects. Statistical significance was not attained for the Caribbean group.

\subsubsection{Self-assessed Academic Ability}

As a subjective measure of the educational aspects of adaptation, students were asked to compare their academic ability with that of their Canadian counterparts on a five-point scale $(1=$ well below average to $5=$ well above average). Slightly more than half of the Hong Kong students $(n=190$, $51.6 \%)$ considered themselves as "average." About one-third selected the "above average" ( $n=98$, $26.6 \%)$ or "well above average" ( $n=22,6.0 \%)$ category. The Caribbean students assessed their ability more favourably as a higher percentage rated themselves as "well above average" $(n=12,19.0 \%)$. Almost four-fifths reported that they were "above average" $(n=18,28.6 \%)$ or "average" $(n=32$, $50.8 \%)$.

\subsubsection{Satisfaction with School Life}

A ten-item scale was constructed to assess students' satisfaction with school life using a five-point scale $(1=$ very dissatisfied to $5=$ very satisfied). As shown in Table 2 , the Hong Kong students were most satisfied with their relations with other students $(M=3.84, S D=.75)$, followed by academic program $(M=3.74, S D=.83)$ and helpfulness of teachers $(M=3.63, S D=.94)$. In contrast, extracurricular activities $(M=3.25, S D=1.05)$, language training programs $(M=3.32, S D=.96)$, and teaching quality of the teachers $(M=3.33, S D=.95)$ were items with which they were least satisfied. The Caribbean students were most pleased with their relations with other students $(M=4.42, S D=$ $.79)$, helpfulness of teachers $(M=4.18, S D=.88)$, and school facilities $(M=4.16, S D=.90)$, but were least satisfied with the grading and examination system $(M=3.85, S D=.85)$, language training $(M=$ $3.83, S D=.96)$, and academic program $(M=3.78, S D=.94)$.

Table2. Satisfaction with various aspects of school life

\begin{tabular}{|l|l|l|l|l|}
\hline & Hong Kong & \multicolumn{2}{l|}{ Caribbean } \\
\hline & M & SD & M & SD \\
\hline 1. My relations with other students. & 3.84 & .75 & 4.42 & .79 \\
\hline 2. My academic program. & 3.74 & .83 & 4.18 & .88 \\
\hline 3. Helpfulness of my teachers. & 3.63 & .94 & 4.16 & .90 \\
\hline 4. School facilities. & 3.57 & .91 & 4.12 & .79 \\
\hline 5. Friendliness of Canadian students. & 3.46 & .91 & 4.09 & 1.00 \\
\hline 6. Grading and examination system. & 3.43 & .99 & 3.98 & .93 \\
\hline 7. Counselling services provided. & 3.33 & .90 & 3.91 & 1.05 \\
\hline 8. Teaching quality. & 3.33 & .95 & 3.85 & .85 \\
\hline 9. Language training programs offered. & 3.32 & .96 & 3.83 & .96 \\
\hline 10. Extra-curricular activities provided. & 3.25 & 1.05 & 3.78 & .94 \\
\hline
\end{tabular}

\subsection{Social Aspects of Adaptation}

\subsubsection{Participation in Community Activities}

As an objective measure of the social aspects of adaptation, students were asked to indicate their frequency of participation in religious, recreational, community, and political organizations using a five-point scale ( $1=$ never to $5=$ very often or everyday). The Hong Kong students were found to participate more actively in religious $(M=2.28, S D=1.26)$ than recreational $(M=1.80, S D=.99)$ or community $(M=1.42, S D=.73)$ organizations. The Caribbean students were relatively active in both religious $(M=2.96, S D=1.49)$ and recreational $(M=2.77, S D=1.48)$ organizations.

\subsubsection{Experience in Making Friends with Canadians and Social Network}

Students' experience in making friends with Canadians (i.e., individuals not belonging to their ethnic group) was a subjective measure of their social adaptation measured on a five-point scale $(1=$ very easy to $5=$ very difficult $)$. While relatively few Hong Kong students $(n=35,9.5 \%)$ considered it "very easy" to make friends with Canadians, more than two-fifths $(n=26,41.9 \%)$ of the Caribbean 
counterparts gave the same response. Approximately a quarter of the Hong Kong students chose "fairly difficult" ( $n=78,21.3 \%)$ or "very difficult" ( $n=15,4.1 \%)$, whereas only less than one-tenth of the Caribbean students $(n=6,9.7 \%)$ made use of the same categories. Concerning the people with whom they spent their leisure time, most Chinese students $(n=281,80.1 \%)$ were found to spend most of their leisure time with family, relatives, or friends from Hong Kong and only $16.8 \%(n=59)$ actually spent their leisure time with non-Chinese Canadian students. Nearly half of the Caribbean students, on the other hand, reported having spent most their leisure time with their family, friends, or schoolmates from their homeland $(n=42,66.7 \%)$ or with their non-Caribbean Canadian friends $(n=$ $9,16.4 \%)$.

\subsection{Cultural And Linguistic Aspects of Adaptation}

\subsubsection{English Language Training}

Language learning was based on students' enrollment in English Language or English as a Second Language (ESL) courses in the previous two semesters. About half of the Hong Kong students $(n=$ $168,45.8 \%)$ enrolled in regular English courses, whereas slightly more than a quarter $(n=100$, $27.2 \%)$ took ESL courses. An overwhelming majority of the Caribbean students $(n=51,83.6 \%)$, however, enrolled in regular English courses.

\subsubsection{Self-rated English Ability}

Students were asked to rate their ability in (a) speaking English, (b) reading English, (c) understanding English, and (d) writing English on a five-point scale $(1=$ very unsatisfactory to $5=$ very satisfactory). The Caribbean students assessed their ability more favourable in all four areas of skills. Notably, both the Hong Kong $(M=3.27, S D=1.13)$ and Caribbean $(M=4.85, S D=.36)$ students considered their ability in understanding spoken English their strongest area. The area in which the Hong Kong $(M=2.72, S D=1.06)$ and Caribbean $(M=4.67, S D=.63)$ students regarded as having the greatest difficulty was writing skills.

\subsubsection{Frequency of English usage}

Students indicated on a five-point scale ( $1=$ ethnic/first language only to $5=$ English only $)$ the language they used when speaking to parents, siblings, best friends, best schoolmates, and family physician. The Hong Kong students used the English language less frequently as the mean scores for the five items were relatively low, ranging from 1.46 to 2.18 , whereas the Caribbean group demonstrated a much higher frequency of English usage, with scores ranging between 4.27 and 4.81.

\subsubsection{Exposure to English and Ethnic Media}

Frequency of exposure to English and ethnic media, including T.V. programs, radio broadcasts, newspapers, and magazines, was used as an objective measure of cultural adaptation. It was assessed using a five-point scale $(1=$ never; $2=$ rarely or once every few months; $3=$ occasionally or once every few weeks; $4=$ sometimes or once every few days; $5=$ very often or daily). Students from Hong Kong reported greater exposure to all four types of mass media in their ethnic language, whereas Caribbean students had greater exposure to the four types of media in the English language.

\subsubsection{Perceived Cultural Differences}

Students expressed the extent to which they perceived ten specific customs and values as similar to or different from their own way of thinking (i.e., the concept of "internalization" as specified in the model) using a five-point scale ( $1=$ very different to $5=$ very similar). As shown in Table 3 , the Hong Kong students agreed that they shared with members of the mainstream society the same "ideas about what is $\operatorname{sad}^{\prime}(M=2.98, S D=.92)$, "ideas about what is funny" $(M=2.85, S D=.97)$, and "openness to new ideas" $(M=2.82, S D=.94)$. On the contrary, they considered their views on "attitudes towards sex" $(M=2.32, S D=.98)$, "children's respect for their parents" $(M=2.40, S D=1.02)$, and "students' respect for their teachers" $(M=2.25, S D=1.03)$ to be different. The Caribbean students seemed to share the same "ideas about what is sad" $(M=3.79, S D=1.23)$, "subjects which should not be discussed" $(M=3.44, S D=1.34)$, and "the degree of friendliness and intimacy between unmarried men and women" $(M=3.36, S D=1.49)$ with Canadians. They were uncomfortable with "students' 
The Adaptation Experiences of Hong Kong and Caribbean Adolescent Immigrants in Canada: A Multivariate Analysis

respect for teachers" $(M=2.13, S D=1.48)$, "children's respect for parents" $(M=2.34, S D=1.60)$, and "people's respect for the elderly" $(M=2.87, S D=1.65)$.

Table3. Perceived cultural differences

\begin{tabular}{|l|l|l|l|l|}
\hline & \multicolumn{2}{l|}{ Hong Kong } & \multicolumn{2}{l|}{ Caribbean } \\
\hline & $\mathrm{M}$ & $\mathrm{SD}$ & $\mathrm{M}$ & $\mathrm{SD}$ \\
\hline 1. Idea about what is sad. & 2.98 & .92 & 3.79 & 1.23 \\
\hline 2. Ideas about what is funny. & 2.85 & .97 & 3.28 & 1.37 \\
\hline 3. Openness to new ideas. & 2.82 & .94 & 3.34 & 1.28 \\
\hline 4. People's respect for the elderly. & 2.80 & 1.23 & 2.87 & 1.65 \\
\hline 5. Subjects which should not be discussed. & 2.70 & .87 & 3.44 & 1.34 \\
\hline 6. Tolerance of others. & 2.59 & .97 & 3.20 & 1.42 \\
\hline $\begin{array}{l}\text { 7. The degree of friendliness and intimacy between unmarried } \\
\text { men and women. }\end{array}$ & 2.54 & .99 & 3.36 & 1.49 \\
\hline 8. Students' respect for their teachers. & 2.25 & 1.03 & 2.13 & 1.48 \\
\hline 9. Children's respect for their parents. & 2.40 & 1.02 & 2.34 & 1.60 \\
\hline 10. Attitude towards sex. & 2.32 & .98 & 2.87 & 1.44 \\
\hline
\end{tabular}

\subsection{Identification with Canada \& Homeland and Self-identification}

Identification involves the modification of the immigrant's own sense of identity and a transference of loyalty from the country of origin to the new. As shown in Table 4, students from Hong Kong were particularly interested in issues, events, and affairs of their homeland $(M=3.70, S D=1.09)$. The lowest mean value was associated with the amount of time they spent with non-Chinese Canadians $(M$ $=2.72, S D=1.04)$ and sense of belonging to Canada $(M=2.72, S D=1.00)$. Students in the Caribbean group indicated their strong interest in issues, events, and affairs of their ethnic homeland $(M=4.31, S D=.86)$, but also expressed a strong positive feeling about being Canadian $(M=3.91, S D$ $=.94)$. Regarding self-identification, over half of the Hong Kong students $(n=210,57.4 \%)$ identified themselves as "Hongkonger," followed by those considered themselves as "Chinese" $(n=62,16.9 \%)$, "Chinese-Canadian" ( $n=59,16.1 \%)$, or "Canadian" $(n=4,1.1 \%)$. Among the Caribbean students, labels such as "West Indian" ( $n=11,17.5 \%)$, "West Indian Canadian" $(n=10,15.9 \%)$, "Black" $(n=$ $10,15.9 \%)$, and "Caribbean" $(n=9,14.3 \%)$ were chosen.

Table4. Identification with homeland and Canada

\begin{tabular}{|c|c|c|c|c|}
\hline & \multicolumn{2}{|c|}{ Hong Kong } & \multicolumn{2}{|c|}{ Caribbean } \\
\hline & M & SD & M & SD \\
\hline \multicolumn{5}{|l|}{ Canada } \\
\hline 1. I am very interested in issues, events, or affairs concerning Canada. & 3.13 & 1.03 & 3.83 & .81 \\
\hline 2. I have a strong positive feeling about being Canadian. & 2.92 & .95 & 3.91 & .94 \\
\hline 3. I have a strong sense of belonging to Canada. & 2.72 & 1.00 & 3.79 & 1.04 \\
\hline $\begin{array}{l}\text { 4. I find it easy to make friends with Canadians who are not of my own ethnic } \\
\text { group. }\end{array}$ & 3.04 & .90 & 3.47 & 1.30 \\
\hline 5. I seldom spend time with Canadians who are not of my own ethnic group. & 2.72 & 1.04 & 3.26 & 1.09 \\
\hline \multicolumn{5}{|l|}{ Homeland } \\
\hline 1. I am very interested in issues, events, or affairs concerning my home country. & 3.70 & 1.09 & 4.31 & .86 \\
\hline 2. I feel a strong attachment towards my own ethnic group. & 3.65 & 1.01 & 3.85 & 1.06 \\
\hline $\begin{array}{l}\text { 3. I am active in organizations or social groups that include mostly people of my } \\
\text { own ethnic group. }\end{array}$ & 2.73 & .86 & 2.78 & 1.26 \\
\hline
\end{tabular}

\subsection{Gratification with Life}

Students were presented with a list of problems and were asked to indicate the extent to which these problems concerned them using a five-point scale $(1=$ very unimportant to $5=$ very important $)$. As displayed in Table 5, the top three issues that were of concern to the Hong Kong students included (1) doing well in school $(M=4.32, S D=.84)$; (2) discrimination against my race $(M=3.79, S D=.99)$; and (3) unpleasant treatment by teachers $(M=3.65, S D=1.13)$, whereas the three major issues identified by the Caribbean students were (1) doing well in school $(M=4.59, S D=.77)$; (2) discrimination against my race $(M=3.86, S D=1.40)$; and (3) financial situation of my family $(M=$ $3.85, S D=1.24)$. 
The Adaptation Experiences of Hong Kong and Caribbean Adolescent Immigrants in Canada: A Multivariate Analysis

Table5. Gratification with life

\begin{tabular}{|l|l|l|l|l|}
\hline & Hong Kong & \multicolumn{2}{l|}{ Caribbean } \\
\hline & M & SD & M & SD \\
\hline 1. Doing well in school. & 4.32 & .84 & 4.59 & .77 \\
\hline 2. Discrimination against my race. & 3.79 & .99 & 3.86 & 1.40 \\
\hline 3. Unpleasant treatment by teachers. & 3.65 & 1.13 & 3.32 & 1.48 \\
\hline 4. Financial situation of my family. & 3.50 & 1.23 & 3.85 & 1.24 \\
\hline 5. Separation from friends/relatives in home country. & 3.41 & 1.19 & 3.81 & 1.35 \\
\hline 6. Unfriendliness of Canadians. & 3.39 & 1.10 & 3.07 & 1.42 \\
\hline 7. My family's adjustment to this country. & 3.32 & 1.07 & 3.24 & 1.30 \\
\hline 8. Pressure of school work. & 3.22 & 1.19 & 3.51 & 1.37 \\
\hline 9. Adjusting to Canadian culture. & 3.03 & 1.04 & 2.98 & 1.40 \\
\hline 10. Getting used to the climate. & 2.74 & 1.13 & 3.03 & 1.45 \\
\hline 11. Adjusting to Canadian food. & 2.38 & 1.11 & 2.61 & 1.49 \\
\hline
\end{tabular}

\subsection{Discrimination Experience}

A total of 89 (24.5\%) Chinese and 10 (16.7\%) Caribbean students reported personal discrimination experience due to their ethnic and cultural background. Students were asked to provide a brief description of their worse experience. Examples of the written accounts given by the respondents, including their place of origin, sex, and length of residence in Canada, are presented below.

My English teacher does not grade my assignments fairly. She has told me that being a Chinese student, I should be happy if I am given a passing grade [trans.]. (HK/male/3 years and 10 months)

Sometimes, while we are speaking Cantonese, some Canadians will give us a dirty look. Or makes us feel uncomfortable. Also, some friends told me that some teacher does not like HK people or Chinese. They will be harsh to those Chinese [sic.]. (HK/female/ 2 years and 9 months)

Some black guys said "Dirty chink!" to me in school [sic.]. (HK/male/9 months)

I was discriminated against by Canadians in school. They used foul language and called me names. They just don't respect Chinese people [trans.]. (HK/female/2 years and 10 months)

I was being called a Chinese pig. (HK/female/l year and 9 months)

The black guys pick on me. When I don't want to talk to them, they swear at me. (Jamaical female/2 years)

People treat me differently because I hang out with a white guy. (Trinidad/female/4 years and 3 months)

In addition, students also spoke of their discrimination experiences outside the schools:

I work part-time as a salesperson. Once when I was talking to a customer in English, that person spoke to me rather sarcastically, suggesting that I should go back to my country of origin. (HK/female/4 years)

I was asking for help and they (all Canadians with blonde hair) looked at one another. And then they said no, which is very obvious that they did it deliberately [sic.] (HK/female/2 years and 4 months)

Once I went with my brother to take TTC bus, we asked the driver to give us transfer but he wasn't give us but we saw he gave to other people - Canadian passengers [sic.]. (HK/female/5 years and 6 months)

When I was talking to my friends in Cantonese in a public place, some people said some bad words to us. They told us to speak in English. [trans.]. (HK/female/1 year and 2 months)

\subsection{Future Plans}

A vast majority of the Hong Kong students $(n=326,89.1 \%)$ planned to enter university upon completion of their high school education, whereas only two-fifths of the Caribbean counterparts $(n=$ 24, 40.0\%) indicated a similar intention. Most Caribbean students expressed an interest in attending community college $(n=25,41.7 \%)$ or seeking employment $(n=7,11.7 \%)$ upon completion of high school. In addition, exactly half of the Hong Kong students $(n=184,50.0 \%)$ and less than half of their Caribbean counterparts $(n=27,46.6 \%)$ indicated that they would eventually move back to their homeland. 
The Adaptation Experiences of Hong Kong and Caribbean Adolescent Immigrants in Canada: A Multivariate Analysis

\subsection{Multivariate Analysis of Adaptation}

Using the thirteen different scales that were constructed to measure the different aspects of adaptation, a one-way MANOVA was performed to compare the various adaptation scores of the two groups. A significant multivariate main effect was found (Wilks $\lambda=.300, F(13,387)=69.354, p<.001$ ). As displayed in Table 6, the univariate F-tests of MANOVA show that ten of the thirteen scales, including school life $(F(1,399)=46.10, p<.000)$, perceived cultural differences $(F(1,399)=16.10$, $p<.000)$, community participation $(F(1,399)=49.17, p<.000)$, identification with Canada $(F(1$, $399)=39.71, p<.000)$, identification with homeland $(F(1,399)=79.49, p<.000)$, English usage $(F(1,399)=607.09, p<.000)$, English proficiency $(F(1,399)=184.99, p<.000)$, English media exposure $(F(1,399)=96.38, p<.000)$, academic ability $(F(1,399)=14.57, p<.000)$, and experience in making friends with Canadians $(F(1,399)=17.05, p<.000)$ attained statistical significance.

In particular, the Caribbean students expressed higher levels of satisfaction with the various aspects of school life, considered their values more similar to those of the Canadians, participated more actively in community activities, reported higher levels of satisfaction with their English ability, used English more frequently, indicated a greater exposure to various English media, considered it relatively easy to make friends with Canadians, and rated their academic ability higher. On the contrary, the Hong Kong students achieved higher scores on the identification with home country and identification with Canada scales.

It is worth noting that although academic performance was significant only at $p=.075$, the mean values reflected that the Hong Kong students $(M=76.97, S D=11.09)$ outperformed their Caribbean counterparts $(M=73.98, S D=10.41)$. The average grade was based on the courses completed in the previous term. The level of difficulty of the courses taken by the students, however, was not taken into account. Based on the fact that only $40.0 \%(n=24)$ of the Caribbean students planned to enter university upon completion of their high school education, it could reasonably be assumed that the Hong Kong students were more likely to have completed advanced (university-bound) rather than basic (vocational) or general (college-bound) courses.

Table6. One-way MANOVA univariate F-tests of major adaptation scores

\begin{tabular}{|c|c|c|c|c|c|c|}
\hline Measures of Adaptation & \multicolumn{2}{|c|}{ Hong Kong } & \multicolumn{2}{|c|}{ Caribbean } & \multirow[b]{2}{*}{$\mathrm{F}$} & \multirow[b]{2}{*}{$\begin{array}{c}\text { Significance } \\
\text { of F }\end{array}$} \\
\hline & $\mathrm{M}$ & SD & $\mathrm{M}$ & $\mathrm{SD}$ & & \\
\hline 1. School life & 3.489 & .582 & 4.080 & .486 & 46.10 & .000 \\
\hline 2. Academic performance & 76.97 & 11.094 & 73.98 & 10.407 & 3.18 & .075 \\
\hline 3. Academic ability & 3.196 & .860 & 3.694 & .822 & 14.57 & .000 \\
\hline 4. Perceived cultural differences & 2.618 & .582 & 3.012 & .989 & 16.10 & .000 \\
\hline 5. English media exposure & 2.931 & .786 & 4.121 & .857 & 96.38 & .000 \\
\hline 6. Ethnic media exposure & 3.206 & .731 & 3.350 & 1.372 & 1.29 & .257 \\
\hline 7. English usage & 1.908 & .651 & 4.431 & .804 & 607.09 & .000 \\
\hline 8. English proficiency & 2.967 & .905 & 4.752 & .405 & 184.99 & .000 \\
\hline 9. Gratification with life & 3.335 & .615 & 3.468 & .823 & 1.83 & .177 \\
\hline 10. Identification with Canada & 2.960 & 699 & 2.277 & .785 & 39.71 & .000 \\
\hline 11. Identification with homeland & 3.362 & .720 & 2.354 & .880 & 79.49 & .000 \\
\hline 12. Community participation & 1.678 & .598 & 2.372 & .941 & 49.17 & .000 \\
\hline $\begin{array}{l}\text { 13. Experience in making friends } \\
\text { with Canadians }\end{array}$ & 3.301 & 1.032 & 3.959 & 1.136 & 17.05 & .000 \\
\hline
\end{tabular}

\subsection{Major Determinants of Overall Adaptation}

Multiple OLS regression analysis was used to explore the major determinants of immigrant students' overall adaptation experiences. The outcome variable was an additive score $(M=6.18, S D=2.35)$ based on the following two items measured on a five-point scale ranging from 1 (extremely unlikely) to 5 (extremely likely): (1) the extent to which they would encourage their friends and relatives in their country of origin to emigrate to Canada $(M=3.00, S D=1.66)$ and (2) the extent to which they would prefer to stay in Canada based on their lived experience in this country $(M=3.16, S D=1.34)$. 
The Adaptation Experiences of Hong Kong and Caribbean Adolescent Immigrants in Canada: A Multivariate Analysis

A total of twelve predictor variables were included in the regression model. Educational reasons for emigration $(M=12.13, S D=2.68)$, political reasons for emigration $(M=10.59, S D=3.00)$, cultural reasons for emigration $(M=12.76, S D=3.53)$, and economic reasons for emigration $(M=6.94, S D=$ 3.09) were multiple-item scales measured using a five-point scale $(1=$ very unimportant to $5=$ very important). These four scales were internally consistent, with Cronbach's alpha reliability coefficients of $.83, .76, .73$, and .79 respectively. Concerning the personal and family characteristics, sex $(1=$ male; $0=$ female), presence of parent $(s)$ in Canada $(1=$ present; $0=$ absent $)$, and prior experience in Canada $(1=$ yes; $0=$ no) were treated as dichotomous variables. Socio-economic status $(M=2.93$, $S D=.70$ ) was measured on a five-point scale ranging from 1 (low) to 5 (high). With regard to the three variables dealing with lived experiences in Canada, discrimination experience $(1=$ yes; $0=$ no) was measured as a categorical variable. Experience in making friends with Canadians $(M=3.41, S D$ $=1.08)$ was measured on a five-point scale $(1=$ very easy to $5=$ very difficult $)$. Academic experience $(M=3.74, S D=.85)$ was also assessed on a five-point scale $(1=$ very dissatisfied to $5=$ very satisfied). An additional variable, ethnic group ( $1=$ Hong Kong; $0=$ other $)$, was included in the model for group comparison purposes.

As displayed in Table 7, the multiple OLS regression model was found to be statistically significant $(F(12,418)=6.997, p<.001)$ and $14.3 \%$ of the variance was accounted for. Six variables, including political $(\beta=.151, p<.01)$ and economic $(\beta=.123, p<.05)$ reasons for immigration, presence of a parent in Canada $(\beta=.091, p<.05)$, prior experience in Canada $(\beta=.095, p<.05)$, experience in making friends with Canada $(\beta=.155, p<.001)$, and ethnic group $(\beta=-.192, p<.05)$ were found to be significantly associated with overall adaptation. Specifically, respondents who stressed the importance of political or economic reasons for emigration, visited Canada as a tourist or studied in Canada on student authorization prior to emigration, expressed more favourable experience in making friends with Canadians, reported having at least one parent residing in Canada, and emigrated from the Caribbean were found to report a more positive overall adaptation experience.

Table7. Unstandardized and standardized ordinary least-squares regression coefficients for effects of sociodemographic and background variables on overall adaptation

\begin{tabular}{|l|l|l|}
\hline & $\mathbf{b}$ & $\beta$ \\
\hline Reasons for emigration & & \\
\hline Educational & -.039 & -.045 \\
\hline Political & .119 & $.151^{* *}$ \\
\hline Cultural & .039 & .056 \\
\hline Economic & .095 & $.123^{*}$ \\
\hline Individual and family characteristics & & \\
\hline Sex & .175 & .038 \\
\hline Presence of parent in Canada & .527 & $.091^{*}$ \\
\hline Socio-economic Status & -.190 & -.047 \\
\hline Prior experience in Canada & .485 & $.095^{*}$ \\
\hline Lived experiences in Canada & & \\
\hline Discrimination experience & -.153 & -.028 \\
\hline Experience in making friends with Canadians & .335 & $.155 * * *$ \\
\hline Academic experience & .145 & .053 \\
\hline & & \\
\hline Ethnic Group & -1.261 & $-.192 * * *$ \\
\hline Constant) & & 1.053 \\
\hline $\mathrm{F}$ & & $6.997^{* * *}$ \\
\hline $\mathrm{R}^{2}$ & \multicolumn{2}{|l|}{} \\
\hline Adjusted $\mathrm{R}^{2}$ & & .143 \\
\hline $\mathrm{N}$ & & 430 \\
\hline
\end{tabular}

$* p<.05 ; * * p<.01 ; * * * p<.001$

\section{Discussion AND CONCLUSION}

This investigation contributes to the study of adaptation of minority immigrants in several ways. First, it examines the perceived outcomes of Chinese immigrants, now one of the largest visible minority groups in Canada. Second, this study focuses on adolescent immigrants whose experiences have 
received relatively little previous research attention. Third, this investigation disentangles the various socio-demographic and situational variables that significantly affect immigration experience. Concerning the major determinants of the overall adaptation experiences of the Hong Kong and Caribbean adolescent immigrants, this research effort has examined the impact of three categories of variables, including motivations for emigration, socio-demographic characteristics, and lived experiences in Canada. With respect to motivations for emigration, the more positive adaptation experience exhibited by those whose motives for emigration were politically and economically oriented may be due to their perception of Canada as a politically stable country. Interestingly, those who put greater emphasis on economic factors for emigration expressed more positive adaptation experiences. This could be related to their perceived significant improvement in the economic aspect of their lives. Moving to Canada from one of the most densely-populated cities in the world or from countries with limited living space and consumer convenience, these young immigrants might consider the possession of a house and a motor vehicle, which is common among ordinary Canadian residents, as an indicator of improved economic well-being.

As well, the presence of a parent in the household was indicative of their commitment to make Canada a permanent home. In fact, the absent father family in the Hong Kong Chinese community has been dubbed the "astronaut family." An "astronaut family" is one in which one spouse, usually the husband, leaves the family behind in Canada and returns to the homeland to continue with business activities or work. The reluctance to give up well-paid jobs in Hong Kong and difficulties in securing comparable jobs in Canada are the principal factors that contribute to the formation of these "absent-parent families." As regards lived experiences in Canada, it is not difficult to understand that friendship (Claes, 1992; Ying \& Liese, 1994) was a major issue of concern among these school-aged immigrants. Consistent with the literature on socio-cultural and educational adaptation of immigrants, experience in making friends with members of the host society (Chow, 2006; Gilman, 2001) was found to be positively related to the outcome variable. The more positive adaptation experience reported by individuals who had visited Canada as tourists or studied in this country as foreign students prior to emigration was expected as they would be able to assist their families to make a more informed decision regarding emigration to Canada. The finding that the Caribbean adolescent immigrants reported a more positive overall adaptation experience could be attributed to their greater emphasis on economic and educational reasons for emigration. They were more satisfied as Canada was able to offer them better opportunities for their future.

One rather disturbing finding is the notable proportion of the Hong Kong (24.5\%) and Caribbean (16.7\%) immigrant students who have experienced discrimination. According to Romero et al. (2007), discrimination is one of the most significant risk factors for psychological adaptation of adolescent immigrants. This is a cause for concern as there is strong empirical evidence demonstrating the association between discrimination and poorer adjustment in terms of lower self-esteem and higher levels of depressive symptoms (Bankston \& Zhou, 2002; Cristini et al., 2011; Greene, Way, \& Pahl, 2006; Juang \& Cookston, 2009) and the negative impact of discrimination on educational outcomes (Alfaro et al., 2009; DeGarmo \& Martinez Jr., 2006; Benner \& Graham, 2011) among adolescent immigrants.

The results of this study will be beneficial not merely to the various high schools and boards of education, but to all other educational institutions where a body of minority immigrant students is found. Its findings can be used as basic information for developing academic and cultural programs (e.g., orientation programs, ESL programs) and support services (e.g., cross-cultural counselling) to cater to the specific needs of these newly-arrived immigrants. The findings can provide the prospective immigrant students with valuable information concerning the different adaptation problems that they may expect to encounter when they immigrate to Canada. As a result, they may be better and more quickly able to adapt during the transition into a new culture. Additionally, governmental departments which are responsible for formulating immigration policies may also find the results useful.

Several limitations of the present investigation should be noted. Although the study involved students from all the six school boards in Toronto, a non-random sample was used. The reliance on crosssectional data also precludes interpretation of causality. To account for these limitations, it would be 
worthwhile to adopt a longitudinal design to further substantiate the causal relationships among the study variables. In conclusion, assisting the children of immigrants to adapt to their schools and integrate with the larger society should be the primary goals for all immigrant receiving countries. The Hong Kong and Caribbean adolescent immigrants can surely be an asset to their "adopted" country, for they are able to extract the best from both their original and host cultures to their own benefits and make Canada a more colourful and interesting country to live in. Upon completion of their studies, the potential contributions that these adolescent immigrants may make to the various spheres of Canadian society, including social, economic, and political, can hardly be under-estimated.

\section{ACKNOWLEDGEMENTS}

The research on which this article is based was partially funded by the Chinese Professional Association of Ontario and the Chinese Business Association through the Chinese-Canadian History and/or Cultural Fellowship administered by the University of Toronto. The author wishes to dedicate this article to the memory of Wai-ling Chow Cho, Muriel Fung, Roxana Ng, and David N. Wilson and to acknowledge the tenacious support and valuable assistance of Edward B. Harvey, Paul C. Olson, Thomson Yu, Chap Wong, Yau-tsang Chan, Stephen Tam, Sutton Cheung, Yiu-joe Chow, Christopher Chow, Christie Chow, Angel Chow, Tat-kwan Wong, Hannah Toong, Kavan Chan, Simon Kwan, Rebecca Tam, Carol Chan, Simon Hui, Kwok K. Choong, Jim Tsui, and Samuel Wong.

\section{REFERENCES}

[1] Statistics Canada (2003). Canada's ethnocultural portrait: The changing mosaic. Ottawa: Ministry of Industry.

[2] Statistics Canada (2013).National household survey (NHS) profile. 2011 national household survey. Statistics Canada Catalogue no. 99-004-XWE. Ottawa. http://www12.statcan.gc.ca/nh senm/2011/dppd/prof/index.cfm?Lang=E (accessed July 6, 2015).

[3] Chen, S.H., Main, A., Zhou, Q., Bunge, S.A., Lau, N., \& Chu, K. (2015). Effortful control and early academic achievement of Chinese American children in immigrant families. Early Childhood Research Quarterly, 30, 45-56.

[4] Chen, H., \& Lan, W. (1998). Adolescents' perceptions of their parents' academic expectations: Comparison of American, Chinese-American, and Chinese high school students. Adolescence, 33(130), 385-390.

[5] Crystal, D.S., Chen, C., Fuligni, A.J., Stevenson, H.W., Hsu, C.C., Ko, H.J., Kitamura, S., \& Kimura, S. (1994). Psychological maladjustment and academic achievement: A cross-cultural study of Japanese, Chinese, and American high school students. Child Development, 65, 738753.

[6] Eng, S., Kanitkar, K., Cleveland, H.H., \& Herbert, R., Fischer, J., \& Wiersma, J. (2008). School achievement differences among Chinese and Filipino American students: Acculturation and family factors. Educational Psychology, 28, 535-550.

[7] Liu, L.L., Benner, A.D., Lau, A.S., \& Kim, S.Y. (2009). Mother-adolescent language proficiency and adolescent academic and emotional adjustment among Chinese American families. Journal of Youth and Adolescence, 38, 572-586.

[8] Tang, M. (2002). A comparison of Asian American, Caucasian American, and Chinese college students: An initial report. Journal of Multicultural Counseling and Development, 30, 124-134.

[9] Benner, A.D., \& Kim, S.Y. (2009). Experiences of discrimination among Chinese American adolescents and the consequences for socioemotional and academic development. Development Psychology, 45, 1682-1694.

[10] Goto, S., Gee, G., \& Takeuchi, D. (2002). Strangers still? The experience of discrimination among Chinese Americans. Journal of Community Psychology, 30(2), 211-224.

[11] Juang, L., \& Alvarez, A. (2010). Discrimination and adjustment among Chinese American adolescents: Family conflict and family cohesion as vulnerability and protective factors. American Journal of Public Health, 100, 2403-2409.

[12] Chan, S., \& Leong, C.W. (1994). Chinese families in transition: Cultural conflicts and adjustment problems. Journal of Social Distress and the Homeless, 3, 263-281. 
[13] Fu, M. (2002). Acculturation, ethnic identity, and family conflict among first- and secondgeneration Chinese Americans. Unpublished Ph.D. dissertation, Alliant International University.

[14] Lee, B.K., \& Chen, L. (2000). Cultural communication competence and psychological adjustment: A study of Chinese immigrant children's cross-cultural adaptation in Canada. Communication Research, 27(6), 764-792.

[15] Yeh, C., \& Inose, M. (2002). Difficulties and coping strategies of Chinese, Japanese, and Korean immigrant students. Adolescence, 37(145), 69-82.

[16] Florsheim, P. (1997). Chinese adolescent immigrants: Factors related to psychosocial adjustment. Journal of Youth and Adolescence, 26(2), 143-163.

[17] Fuligni, A., Yip, T., \& Tseng, V. (2002). The impact of family obligation on the daily activities and psychological well-being of Chinese American adolescents. Child Development, 73(1), 302314.

[18] Lin, M.C., Endler, N.S., \& Kocovski, N.L. (2001). State and trait anxiety: A cross-cultural comparison of Chinese and Caucasian students in Canada. Current Psychology, 20(1), 95-111.

[19] Qin, D.B. (2008). Doing well vs. feeling well: Understanding family dynamics and the psychological adjustment of Chinese immigrant adolescents. Journal of Youth and Adolescence, $37,22-35$.

[20] Lee, J.J., \& Kimberlin, C. (2015). Life satisfaction between Chinese-immigrant adolescents and their counterparts in the United States and China. Open Journal of Social Sciences, 3, 118-124.

[21] James, D.C.S. (1997). Coping with a new society: The unique psychosocial problems of immigrant youth. Journal of School Health, 67(3), 98-102.

[22] Schnittker, J. (2002). Acculturation in context: The self-esteem of Chinese immigrants. Social Psychology Quarterly, 65(1), 56-76.

[23] Suzuki, L.K., \& Greenfield, P.M. (2002). The construction of everyday sacrifice in Asian Americans and European Americans: The roles of ethnicity and acculturation. Cross-Cultural Research, 36(3), 200-228.

[24] Leung, C. (2001). The Socio-cultural and psychological adaptation of Chinese migrant adolescents in Australia and Canada. International Journal of Psychology, 36(1), 8-19.

[25] Lay, C., \& Verkuyten, M. (1999). Ethnic identity and its relation to personal self-esteem: A comparison of Canadian-born and foreign-born Chinese adolescents. The Journal of Social Psychology, 139(3), 288-299.

[26] Chataway, C.J., \& Berry, J.W. (1989). Acculturation experiences, appraisal, coping, and adaptation: A comparison of Hong Kong Chinese, French, and English students in Canada. Canadian Journal of Behavioural Science, 21, 295-309.

[27] Dyal, J.A., \& Chan, C. (1985) Stress and distress: A study of Hong Kong Chinese and EuroCanadian students. Journal of Cross-Cultural Psychology, 16(4), 447-466.

[28] Lam, C.M. (2001). Adolescent development in the context of Canadian-Chinese immigrant families. Unpublished Ph.D. dissertation, Wilfrid Laurier University.

[29] Minichiello, D. (2001). Chinese voices in a Canadian secondary school landscape. Canadian Journal of Education, 26(1), 77-96.

[30] Yeung, P. (2005). The psychosocial adjustment of Chinese adolescent immigrants in satellite families in Canada. Unpublished M.A. thesis, Simon Fraser University.

[31] Samuel, E., Krugly-Smolska, E., \& Warren, W. (2001). Academic achievement of adolescents from selected ethnocultural groups in Canada: A study consistent with John Ogbu's theory. McGill Journal of Education, 36(1), 61-73.

[32] Goldlust, J., \& Richmond, A.H. (1974). A multivariate model of immigrant adaptation. International Migration Review, 8(2), 193-225.

[33] Chow, H.P.H. (2007). Sense of belonging and life satisfaction among Hong Kong adolescent immigrants in Canada. Journal of Ethnic and Migration Studies, 33(3), 511-520. 
[34] Chow, H.P.H. (1997). In search of a land flowing with milk and honey: The adaptation experiences of uprooted Chinese and Black immigrant students in a multicultural society. Unpublished Ph.D. thesis, University of Toronto.

[35] Claes, M.E. (1992). Friendship and personal adjustment during adolescence. Journal of Adolescence, 15, 39-55.

[36] Ying, Y., \& Liese, L. (1994) Initial adjustment of Taiwan students to the United States: The impact of post-arrival variables. Journal of Cross-Cultural Psychology, 25, 466-477.

[37] Chow, H.P.H. (2006). Vietnamese-Canadian university students in Regina: Socio-cultural and educational adaptation. Canadian Ethnic Studies, XXXVIII (2), 104-112.

[38] Gilman, R. (2001). The relationship between life satisfaction, social interest, and frequency of extracurricular activities among adolescent students. Journal of Youth and Adolescence, 30(6), 749-767.

[39] Romero, A.J., Carvajal, S.C., Valle, F., \& Orduña, M. (2007). Adolescent bicultural stress and its impact on mental well-being among Latinos, Asian Americans, and European Americans. Journal of Community Psychology, 35(4), 519-534.

[40] Bankston, C.L., \& Zhou, M. (2002). Being well vs. doing well: Self-esteem and school performance among immigrant and nonimmigrant racial and ethnic groups. International Migration Review, 36(2), 389-415.

[41] Cristini, F., Scacchi, L., Perkins, D.D., Santinello, M., \& Vieno, A. (2011). The influence of discrimination on immigrant adolescents' depressive symptoms: What buffers its detrimental effects? Psychosocial Intervention, 20(3), 243-253.

[42] Greene, M.L., Way, N., \& Pahl, K. (2006). Trajectories of perceived adult and peer discrimination among Black, Latino, and Asian American adolescents: Patterns and psychological correlates. Developmental Psychology, 42(2), 218-238

[43] Juang, L., \& Cookston, J. (2009). Acculturation, discrimination, and depressive symptoms among Chinese American adolescents: A longitudinal study. Journal of Primary Prevention, 30, 475-496.

[44] Alfaro, E.C., Umana-Taylor, A.J., Gonzales-Backen, M.A., Bamaca, M.Y., \& Zeiders, K.H. (2009). Latino adolescents' academic success: The role of discrimination, academic motivation, and gender. Journal of Adolescence, 32, 941-962.

[45] De Garmo, D.S., \& Martinez, C.R., Jr. (2006). A culturally informed model of academic wellbeing for Latino youth: The importance of discriminatory experiences and social support. Family Relations, 55, 267-278.

[46] Benner, A.D., \& Graham, S. (2011). Latino adolescents' experiences of discrimination across the first 2 years of high school: Correlates and influences on educational outcomes. Child Development, 82(2), 508-519.

\section{AUTHOR's BIOGRAPHY}

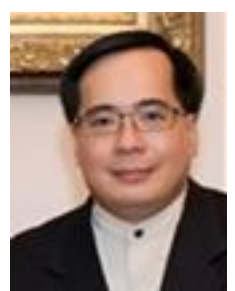

Dr. Henry P.H. Chow (Ph.D., University of Toronto) is a Professor and Graduate Program Co-ordinator in the Department of Sociology \& Social Studies at the University of Regina in Saskatchewan, Canada. His teaching and research interests include ethnic studies, immigration and immigrant settlement, criminology and criminal justice, social gerontology, the sociology of education, the sociology of religion, quantitative analysis, and survey research methods. 